\title{
The impact of an 8-week Pilates-based physical training program on functional mobility: data from a septuagenarian group
}

\author{
Miguel Lima ${ }^{1,2}$, Bruno Silva ${ }^{2,3}$, Sílvia Rocha-Rodrigues ${ }^{2,3,4}$, Pedro Bezerra ${ }^{2,3}$ \\ ${ }^{1}$ Faculty of Education and Sport Sciences, University of Vigo, Pontevedra, Spain; ${ }^{2}$ Escola Superior de Desporto e Lazer \\ de Melgaço, Instituto Politécnico de Viana do Castelo, Viana do Castelo, Portugal; ${ }^{3}$ Research Center in Sports Sciences \\ Health and Human Development, CIDESD, Vila Real, Portugal; 4 Tumor and Microenvironment Interactions Group, i3S, \\ Porto, Portugal
}

\begin{abstract}
Study aim: This study aimed to evaluate the effects of a Pilates-based training program on functional mobility and strength in community-dwelling adults over 70 years old.

Material and methods: Twenty community-dwelling elderly subjects were recruited and randomly assigned to control $(\mathrm{C}=10)$ or Pilates training $(\mathrm{PT}=10)$ groups for 8 weeks (2 times/week). Anthropometric, strength, cardiorespiratory fitness, functional mobility, and static and dynamic balance parameters were assessed before and after the intervention.

Results: The PT group had higher values of lower limb strength $(\mathrm{p}=0.013 d=0.56)$ and 6-minute walking test distance $(\mathrm{p}=0.04 ; d=0.45)$ than the $\mathrm{C}$ group. The PT group also had differences in one leg stance duration and decrease in the Timed Up and Go test. We also observed a positive correlation between muscle strength and cardiorespiratory fitness ( $p<0.01$, $\mathrm{r}=0.62)$, cardiorespiratory fitness and one leg stance, eyes closed, right and left leg $(\mathrm{p}=0.04, \mathrm{r}=0.45 ; \mathrm{p}=0.05, \mathrm{r}=0.45$, respectively).

Conclusions: Eight weeks of Pilates-based physical training induced improvements in skeletal muscle strength and functional mobility of community-dwelling septuagenarians.
\end{abstract}

Keywords: Ageing - Muscle strength - Balance - Functional mobility - Pilates method

\section{Introduction}

The positive growth in life expectancy leads to an increase in the number and percentage of older adults in the world's population In fact, the number of people aged 60 years is expected to nearly triple by 2050 [46]. From a physiological point of view, ageing is driven at the cellular level by random molecular damage that slowly accumulates with age, which likely results in a gradual decline in both physical and mental capacities and a growing risk of comorbidities. However, there is a discrepancy in the main health outcomes among older adults with some 70-year-olds having good health and functional mobility whereas other 70-year-olds experience a considerable decline in physical and/or mental capacity. This decline can be manifested in different levels and functions of the neuromuscular system, such as declines of functional mobility, strength and cardiorespiratory capacity [41] as well as dynamic balance $[5,43]$, which can increase the risk of falls and the risk of developing other health conditions. Such evidence has been closely related with poor quality of life and elevated long-term health-care costs [19, 35].

Physical training has been considered a potent tool to minimize the aging-related deleterious effects [28, 38, 47]. Studies with physical exercise-based programs, including resistance exercises [20], high-intensity training [7], multicomponent approach exercises [10] or Tai Chi [51] demonstrated significant benefits in skeletal muscle structural and functional changes. Among the different types of physical training, the Pilates method has emerged as an important possibility to attenuate and/or revert changes induced by the aging process [8, 9]. Pilates training has an holistic approach, requiring activation and coordination of several muscle groups simultaneously [26]. In fact, Pilates training focuses on correct execution of the six fundamental principles, concentration, control, centering, flowing movement, precision and breathing, and increases 
body awareness with less ground impact and joint stress [9]. However, to the best of our knowledge, few studies have aimed to evaluate the impact of Pilates training on functional mobility among elderly individuals. Therefore, we aimed to analyze the impact of a Pilates-based physical training program in functional mobility and strength in adults over 70 years old.

\section{Materials and methods}

The present study was a prospective, treatment-controlled, study that involved baseline and post-intervention measurements after an 8-week Pilates-based physical training program in an elderly population recruited from north Portugal. The recruitment was based on advertisement and oral information in daily living centers and social events traditionally involving older adults. Researchers explained the conditions for inclusion in the 8-week Pilates-based training program along with local health authorities. Participants were informed of possible significant risks, which mainly included muscular soreness. The approval for the experimental procedures was obtained from the Human Research Ethics Committee of the Polytechnic Institute of Viana do Castelo (PTDC/DTD-DES/0209/2012). Written informed consent was obtained from each participant. All tests were performed by experienced researchers.

\section{Participants}

Giving the inclusion and exclusion criteria and from an estimated potential sample of 237 candidates, 20 community-dwelling elderly, over 70 years old, agreed to participate. The candidates were randomly assigned to the control group ( $\mathrm{C} ; \mathrm{n}=10$, age $75.8 \pm 4.44,5$ men and 5 women) or Pilates training $(\mathrm{PT} ; \mathrm{n}=10$, age $76.5 \pm 5.93,4$ men and 6 women) group. The inclusion criteria were i) motor and physical independence; ii) absence of mobility aids; iii) visual acuity above $20 \%$ and iv) absence of neurological disease. Exclusion criteria included i) any injury that not allow to perform physical activity; ii) the presence of a prosthesis or iii) not able to complete at least $80 \%$ of the total sessions. None of the participants had a history of Pilates training and no drop outs were registered during the intervention period.

Participants completed basic socio-demographic information and current levels of physical activity or exercise, measured based on the following question: "Do you practice sports or physical activity enough to produce sweating or shortness of breath?" [29]. The type and frequency of practice (days per week) were also recorded. In the PT group, 90\% performed physical activity at least 2 times per week and $100 \%$ of participants of the $\mathrm{C}$ group reported non-regular physical activity.

\section{Pilates-based physical training}

The Pilates-based physical training program comprised 2 sessions per week, 60 minutes per session for 8 weeks. All sessions and evaluations were conducted by a specialized and certified Pilates instructor with more than 8 years of experience teaching the Pilates method. According to the development of basic Pilates mat work, the sessions were distributed in 3 progression phases, and adjusted to the participants needs, according to the capability to accomplish the physical standard pattern of the Pilates exercises (progression and regressions) and the presence of discomfort or pain. The first phase included 6 sessions which consisted of the introduction to the Pilates method with standing exercises (abdominal breathing, arm circles, side stretch and chest expansion), pre-Pilates supine exercises (lateral chest breathing, extend leg up and down, toe touch, foot flex and point, scapula mobilization), exercises in the supine position (hundred, roll up, single leg circle, double straight leg stretch, tick tock bent legs and pelvic curl/shoulder bridge), seated exercises (spine stretch forward and single leg stretch. Exercises in the prone position (prone head lift, prone leg lift, half swimming) and finally quadrupedal exercises (cat stretches and balance). In the second phase (from $7^{\text {th }}$ to $11^{\text {th }}$ session), similar exercises as the first phase were performed with the addition of standing exercises (spinal twist, squat and roll down) and the supine exercises (double straight leg stretch). In the third phase (from $12^{\text {th }}$ to $16^{\text {th }}$ session), the pre-Pilates exercises in the supine position were removed and the standing exercises were the main exercises, such as lunges and the quadrupedal transition exercise to the standing position: roll up to standing, as previously described [8]. The $\mathrm{C}$ group subjects received no Pilates training during the 8 weeks of intervention and were encouraged to abstain from beginning any exercise program or changing their current activity levels during this time period.

\section{Anthropometric measures}

The anthropometric measures followed the standard procedures of the International Society for the Advancement of Kinanthropometry [44]. The height was measured to the nearest $0.1 \mathrm{~cm}$ with a portable stadiometer (SECA 217 , Germany). The body weight was assessed on a scale (SECA 760, Germany) to the nearest $0.5 \mathrm{~kg}$. The body mass index (BMI, $\mathrm{kg} / \mathrm{m}^{2}$ ) was determined as the ratio between weight and height squared, and then individuals were categorized according to the WHO International classification [33] as normal weight (18.5 and 24.9), overweight (25.0-29.9) or obese $(\geq 30.0)$. The waist circumference was measured with an inextensible anthropometric tape about the smallest circumference between the ribs and iliac crest, at the end of a normal expiration, to the nearest $0.1 \mathrm{~cm}$. For the thigh circumference, participants 
stood up and the measure was taken at midway between the greater trochanter and lateral tibiae.

\section{Skeletal muscle strength tests}

The skeletal muscle strength of the upper and lower limbs was assessed using the handgrip test and isometric knee extension test, respectively. Handgrip strength in kilograms was measured using a hydraulic hand dynamometer (SH5001, SAEHAN Corporation). Participants performed three repetitions by hand, alternately, right and left, with 1 minute rest between trials. The scores were recorded and the best performance was considered for further analysis. Maximal isometric handgrip strength, measured with a dynamometer according to the standard procedure, has high to excellent inter-tester and test-retest reliability [25].

Isometric knee extension strength was measured on a custom-built chair incorporating an $\mathrm{S}$ shape load cell (VETEK VZ101BS, 1 tonne) with the knee joint fixed at $90^{\circ}$ and the load cell attached to the subject's ankle joint with a strap [4]. As demonstrated by Wang and associates [50], being based on isometric strength, this method presents excellent reliability and reproducibility compared to a laboratory-based Biodex dynamometer.

Three trials were performed on the right leg with a rest period of 1 minute between trials, according to the American Society of Hand Therapists [17]. The best of the three trials was recorded for further analysis.

\section{Cardiorespiratory fitness test}

The 6-minute walking (6MW) test was performed according to the protocol of the American Thoracic Society [42]. This test is an easy and validated field test for assessing cardiorespiratory fitness in the elderly [6]. The participants were asked to walk, as fast as possible, according to a course on a flat and hard surface, for 6 minutes. Verbal encouragement was provided during the test and the maximal distance was recorded in meters. Before the test, the researchers performed a single lap of the course, identifying the turnaround point and the procedure in case the participants become so tired that they had to stop.

\section{Balance tests}

The one leg stance with eyes open and eyes closed was performed for both right and left leg. This test has a high inter-rater reliability, being a valid instrument for assessing balance in different age groups [43]. Participants were instructed to remain barefoot, with a leg elevated, about $10 \mathrm{~cm}$ from the ground, so that the elevated foot was close to, but not in contact with, the lower support leg, and asked to focus on a fixed point on the wall at eye level, during the eyes open test. The upper limbs were stretched out along the trunk. A digital timer was used to measure the time in seconds that the participant remained balanced on one foot. The timing started when the participant took the foot off the ground and ended when: i) the participant used the upper limbs to maintain balance; ii) the participant used the elevated foot to maintain balance; iii) the participant moved the footrest to maintain balance; iv) a maximum of 30 seconds in equilibrium had occurred; and v) the participant opened his/her eyes, in the eyes closed condition. This procedure was performed twice in both tests, with a rest of two minutes between tests. Before testing, subjects were instructed about the procedure and performed two experimental trials of each condition. All subjects performed the right and left leg test randomly with both open and closed eyes. At least five minutes rest was indorsed between the eyes open and the eyes closed tests and the best performance was considered for analyses.

\section{Performance-based measures of functional mobility}

The Timed Up and Go (TUG) is a simple, valid and widely used clinical performance-based measure of lower extremity function, mobility, dynamic balance and fall risk $[3,27]$. The test was performed in accordance with general recommendations, to accomplish consistency conditions [36], in an armless chair with about $46 \mathrm{~cm}$. The test started with the participant sitting on the chair, with back supported, feet shoulder width apart and flat on the ground, and the arms resting on the legs. A cone was placed on the floor, $3 \mathrm{~m}$ from the chair. The following statement was given to the subject: "The purpose of this test is to assess the time it takes to get up, walk three meters along the line, reach the cone, turn around, return to the chair and sit. Walk at your usual speed. When you hear the word "GO" you will perform the test the way it was given." Each participant performed a single trial with the criterion trial before the real trial. The time to perform the TUG test was recorded with a sports watch. The timer started when the patient got up and ended when he/she sat back down fully supporting the buttocks in the chair.

\section{Statistical analyses}

The descriptive statistics, mean and standard deviation were calculated for all variables.

Wilcoxon signed rank and Mann-Whitney tests were applied to compare the differences from baseline to the post-intervention program. Additionally, we calculated effect sizes (ES) as Cohen's d using the pooled standard deviation of the random effects. The ES to non-parametric tests was obtained according to the literature [34]. Associations between variables were examined using Pearson's correlation coefficient. The following correlation scale was adopted [23]: trivial $(r<0.1)$; small $(0.1 \leq r<0.3)$; moderate $(0.3 \leq r<0.5)$; large $(0.5 \leq r<0.7)$; very large $(0.7 \leq r<0.9)$; and nearly perfect $(\geq 0.9)$. All statistical analyses were executed using IBM SPSSStatistics for Windows, version 22.0 (IBM Corp., Armonk, N.Y. USA) with the significance level set at $\mathrm{p}<0.05$. 


\section{Results}

Considering the estimated potential sample of 237 subjects, the total sample was representative according to a confidence level of $95 \%$ with a margin of error of $22 \%$.

As shown in Table 1, no significant differences were found in anthropometric parameters after 8 weeks of Pilates training, except for thigh circumference $(\mathrm{p}<0.05)$. However, a small effect for weight $(d=0.22,70.4 \pm 8.5$ vs.73.4 \pm 14.7$)$ and waist circumference $(d=0.22$ was observed in the PT group compared to the $\mathrm{C}$ group. The BMI classification shows that in the PT group 20\% were classified as overweight and 50\% were obese. In the $\mathrm{C}$ group $40 \%$ were classified as obese and $40 \%$ were overweight.
Table 2 presents skeletal muscle strength for upper and lower limb and cardiorespiratory fitness tests. Although a significant increase was found in lower limb $(34.66 \pm 15.0$ vs. $30.07 \pm 6.1 ; \mathrm{p}=0.013 d=0.56)$ in the Pilates-exercised group after 8 weeks of Pilates training vs. baseline, there was no difference in upper limb muscle strength. The PT group exhibited a better $6 \mathrm{MW}$ test performance after 8 weeks of the Pilates-based program $(476.75 \pm 79.40$ vs. $443.20 \pm 89.94, \mathrm{p}=0.04 ; d=0.45 ;)$.

Balance is usually categorized as static or dynamic balance [24]. Balance is crucial for the performance of daily life actions and movements in elderly that involve high complexity and requiring self-proper body control [45]. Therefore, we evaluated one leg stance with eyes open and closed for both legs and the TUG test before and after

Table 1. Anthropometric measures before and after Pilates-based physical training program

\begin{tabular}{|c|c|c|c|c|c|c|c|c|}
\hline & \multicolumn{3}{|c|}{ Control group } & \multicolumn{3}{|c|}{ Pilates training group } & \multicolumn{2}{|c|}{$\begin{array}{c}\text { Cohen's } d \\
\text { PT vs. C group }\end{array}$} \\
\hline & $\mathrm{BL}$ & PI & $d$ & $\mathrm{BL}$ & PI & $d$ & $\mathrm{BL}$ & PI \\
\hline Age [years] & $75.8 \pm 4.44$ & - & & $76.5 \pm 5.93$ & - & - & - & - \\
\hline Height $[\mathrm{cm}]$ & $\begin{array}{c}160.3 \pm 10.0 \\
{[152.6 ; 168.8]}\end{array}$ & $\begin{array}{c}160.1 \pm 10.0 \\
{[152.1 ; 168.5]}\end{array}$ & $<0.10$ & $\begin{array}{c}156.6 \pm 11.9 \\
{[148.9 ; 171.4]}\end{array}$ & $\begin{array}{c}156.7 \pm 11.6 \\
{[149.2 ; 171.0]}\end{array}$ & 0.15 & $<0.10$ & $<0.1$ \\
\hline Weight $[\mathrm{kg}]$ & $\begin{array}{l}73.4 \pm 14.2 \\
{[61.2 ; 83.9]}\end{array}$ & $\begin{array}{l}73.4 \pm 14.7 \\
{[60.6 ; 83.8]}\end{array}$ & 0.15 & $\begin{array}{c}71.8 \pm 8.4 \\
{[62.6 ; 79.8]}\end{array}$ & $\begin{array}{c}70.4 \pm 8.5 \\
{[70.0 ; 80.0]}\end{array}$ & 0.22 & 0.17 & 0.14 \\
\hline BMI $\left[\mathrm{kg} / \mathrm{m}^{2}\right]$ & $\begin{array}{c}28.4 \pm 4.1 \\
{[25.5 ; 31.3]}\end{array}$ & $\begin{array}{c}28.5 \pm 4.4 \\
{[25.4 ; 31.7]}\end{array}$ & $<0.10$ & $\begin{array}{c}29.6 \pm 4.6 \\
{[26.3 ; 32.9]}\end{array}$ & $\begin{array}{c}29.3 \pm 4.3 \\
{[26.2 ; 32.4]}\end{array}$ & 0.17 & 0.15 & $<0.1$ \\
\hline $\begin{array}{l}\text { Waist } \\
\text { circumference }[\mathrm{cm}]\end{array}$ & $\begin{array}{c}98.5 \pm 10.3 \\
{[89.8 ; 106.4]}\end{array}$ & $\begin{array}{c}99.6 \pm 11.4 \\
{[89.6 ; 107.0]}\end{array}$ & $<0.10$ & $\begin{array}{c}99.4 \pm 5.6 \\
{[92.7 ; 103.5]}\end{array}$ & $\begin{array}{c}97.1 \pm 5.7 \\
{[92.2 ; 100.3]}\end{array}$ & 0.22 & $<0.10$ & $<0.1$ \\
\hline $\begin{array}{l}\text { Thigh } \\
\text { circumference }[\mathrm{cm}]\end{array}$ & $\begin{array}{c}50.9 \pm 4.6 \\
{[47.4 ; 54.9]}\end{array}$ & $\begin{array}{c}50.8 \pm 4.7 \\
{[47.0 ; 54.6]}\end{array}$ & $<0.10$ & $\begin{array}{c}49.6 \pm 6.9 \\
{[43.3 ; 55.9]}\end{array}$ & $\begin{array}{l}53.4 \pm 7.6^{*} \\
{[45.5 ; 58.2]}\end{array}$ & 0.19 & 0.15 & 0.16 \\
\hline
\end{tabular}

Data are expressed as mean \pm SD [95\% confidence interval]; BL - baseline; PI - post-intervention; PT - Pilates training; C group - control group; $d$ - Cohen's $d$; BMI - body mass index; ${ }^{*}$ vs. baseline.

Table 2. Effects of 8-week Pilates-based physical training program on skeletal muscle strength and cardiorespiratory fitness

\begin{tabular}{|c|c|c|c|c|c|c|c|c|}
\hline & \multicolumn{3}{|c|}{ Control group } & \multicolumn{3}{|c|}{ Pilates Training group } & \multicolumn{2}{|c|}{$\begin{array}{c}\text { Cohen's } d \\
\text { PT vs. C group }\end{array}$} \\
\hline & $\mathrm{BL}$ & PI & $d$ & $\mathrm{BL}$ & PI & $d$ & $\mathrm{BL}$ & PI \\
\hline Upper limb [daN] & $\begin{array}{c}31.6 \pm 9.6 \\
{[24.8 ; 39.9]}\end{array}$ & $\begin{array}{c}31.1 \pm 9.9 \\
{[25.6 ; 39.7]}\end{array}$ & $<0.10$ & $\begin{array}{l}29.2 \pm 10.0 \\
{[19.8 ; 41.6]}\end{array}$ & $\begin{array}{l}28.20 \pm 9.0 \\
{[19.1 ; 39.2]}\end{array}$ & 0.17 & 0.10 & 0.17 \\
\hline Lower limb [daN] & $\begin{array}{l}45.1 \pm 19.7 \\
{[30.0 ; 60.3]}\end{array}$ & $\begin{array}{l}45.5 \pm 21.6 \\
{[28.9 ; 62.1]}\end{array}$ & $<0.10$ & $\begin{array}{l}30.1 \pm 12.6 \\
{[17.6 ; 45.2]}\end{array}$ & $\begin{array}{l}34.7 \pm 15.0^{*} \\
{[19.0 ; 52.4]}\end{array}$ & 0.56 & 0.29 & 0.31 \\
\hline $6 \mathrm{MW}$ test $[\mathrm{m}]$ & $\begin{array}{c}577.8 \pm 70.7 \\
{[530.6 ; 639: 6]}\end{array}$ & $\begin{array}{c}546.8 \pm 76.6^{\#} \\
{[497.9 ; 613.7]}\end{array}$ & 0.41 & $\begin{array}{c}443.2 \pm 89.9 \\
{[364.2 ; 545.4]}\end{array}$ & $\begin{array}{c}476.8 \pm 79.4^{*} \\
{[411.0 ; 569.0]}\end{array}$ & 0.45 & 0.63 & 0.36 \\
\hline
\end{tabular}


Table 3. Effects of Pilates-based physical training program on performance-based measures of balance and functional mobility

\begin{tabular}{|c|c|c|c|c|c|c|c|c|}
\hline & \multicolumn{3}{|c|}{ Control group } & \multicolumn{3}{|c|}{ PT group } & \multicolumn{2}{|c|}{$\begin{array}{c}\text { Cohen's } d \\
\text { PT vs.C group }\end{array}$} \\
\hline & $\mathrm{BL}$ & PI & $d$ & $\mathrm{BL}$ & PI & $d$ & $\mathrm{BL}$ & PI \\
\hline \multicolumn{9}{|l|}{ One leg stance } \\
\hline Eyes open, right leg [s] & $\begin{array}{l}5.9 \pm 2.5 \\
{[4.1 ; 8.1]}\end{array}$ & $\begin{array}{c}6.7 \pm 5.8 \\
{[2.5 ; 11.8]}\end{array}$ & $<0.10$ & $\begin{array}{c}5.6 \pm 6.7 \\
{[-0.5 ; 14.0]}\end{array}$ & $\begin{array}{c}12.5 \pm 10.5^{*} \\
{[3.0 ; 25.5]}\end{array}$ & 0.60 & 0.41 & 0.34 \\
\hline Eyes open, left leg [s] & $\begin{array}{c}7.2 \pm 4.1 \\
{[4.4 ; 10.8]}\end{array}$ & $\begin{array}{c}7.9 \pm 4.5 \\
{[5.0 ; 11.8]}\end{array}$ & $<0.10$ & $\begin{array}{c}7.4 \pm 7.1 \\
{[0.3 ; 14.6]}\end{array}$ & $\begin{array}{c}11.9 \pm 10.4^{*} \\
{[1.9 ; 23.3]}\end{array}$ & 0.60 & 0.12 & 0.12 \\
\hline Eyes closed, right leg [s] & $\begin{array}{l}3.0 \pm 1.00 \\
{[2.4 ; 3.9]}\end{array}$ & $\begin{array}{l}2.8 \pm 1.9^{\#} \\
{[1.3 ; 4.4]}\end{array}$ & 0.13 & $\begin{array}{l}1.69 \pm 0.7 \\
{[0.9 ; 2.1]}\end{array}$ & $\begin{array}{l}3.1 \pm 1.4^{*} \\
{[1.5 ; 4.6]}\end{array}$ & 0.63 & 0.67 & 0.24 \\
\hline Eyes open, left leg [s] & $\begin{array}{l}3.0 \pm 0.9 \\
{[2.3 ; 3.8]}\end{array}$ & $\begin{array}{l}2.6 \pm 0.8^{\#} \\
{[2.1 ; 3.3]}\end{array}$ & 0.23 & $\begin{array}{l}2.0 \pm 1.7 \\
{[0.3 ; 3.7]}\end{array}$ & $\begin{array}{l}4.5 \pm 3.4^{*} \\
{[1.2 ; 6.9]}\end{array}$ & 0.54 & 0.44 & 0.14 \\
\hline TUG $[\mathrm{s}]$ & $\begin{array}{c}7.2 \pm 0.9 \\
{[6.4 ; 7.7]}\end{array}$ & $\begin{array}{l}7.7 \pm 1.2^{\#} \\
{[6.7 ; 8.6]}\end{array}$ & 0.35 & $\begin{array}{c}9.6 \pm 1.7 \\
{[7.6 ; 11.3]}\end{array}$ & $\begin{array}{l}7.0 \pm 1.0^{*} \\
{[5.9 ; 8.0]}\end{array}$ & 0.63 & 0.68 & 0.30 \\
\hline
\end{tabular}

Data are expressed as mean $\pm \mathrm{SD}[95 \% \mathrm{CI}] ; \mathrm{BL}$ - baseline; PI - post-intervention; $d$ - Cohen's $d$; PT - Pilates training group; C group - control group; TUG - Timed Up and Go; ${ }^{*}$ vs. baseline; ${ }^{*}$ vs. C group at baseline.

8 weeks of Pilates training. We observed that elderly from the PT group clearly improved one leg stance related parameters and the TUG test (Table 3 ).

For one leg stance, the PT group increased duration with eyes open for right leg $(\mathrm{p}<0.01 ; d=60)$ and left leg $(\mathrm{p}<0.01 ; d=0.60)$ as well as with eyes closed for right leg $\mathrm{p}<0.01, d=0.60)$ and left leg $(\mathrm{p}<0.01 ; d=0.54)$ after the 8 -week Pilates-based physical training program. The duration of the TUG test decreased significantly in the PT group from baseline to post-intervention moments $(9.6 \pm 1.7$ vs. $7.0 \pm 1.0 ; \mathrm{p}<0.01, d=0.63)$. There were no statistically significant differences in these parameters in the PT group vs. C group after intervention, but a moderate-sized effect was seen for duration of one leg stance eyes open, right leg $(d=0.34)$ and for the TUG test $(d=0.30)$.

Overall, considering muscle strength, cardiorespiratory fitness and balance parameters, we observed a positive correlation between handgrip strength and isometric knee extension $(\mathrm{p}<0.01, \mathrm{r}=0.62)$; handgrip strength and cardiorespiratory fitness $(\mathrm{p}<0.01, \mathrm{r}=0.62)$; cardiorespiratory fitness and one leg stance, eyes closed, right and left leg $(\mathrm{p}=0.04, \mathrm{r}=0.46 ; \mathrm{p}=0.05, \mathrm{r}=0.45)$, as shown in Figure 1.

\section{Discussion}

The present findings suggest that 8 weeks of Pilatesbased physical training can be a valid alternative method as a relevant strategy to improve cardiorespiratory fitness, lower limb muscle strength and both dynamic and static balance in the elderly over 70 years old. Furthermore, the attendance was $92 \%$, which may indicate high motivation of such a population to undertake this type of exercise training.

Previous studies indicate that regular participation in a short training program had a positive impact on anthropometric variables such as weight loss [1], increase of lean body mass $[20,30]$ or the reduction of fat mass [20]. However, other studies [12] have shown that it is unclear whether the physical training has an independent effect on the lipid profile or is dependent on associated weight loss. Regarding the effects of the PM intervention in anthropometric variables, the results are contradictory $[11,15]$. For example, Fourie et al. (2013) [18] reported a significant improvement in lean mass and significant decreases in fat mass, from pre - to post-testing, while Vécseyné et al. (2013) [48] and Fernández and Benítez (2013) [16] did not find significant differences in BMI and muscle mass. The present study findings are in line with Vécseyné et al. (2013) [48] and Fernández and Benítez (2013) [16], as no significant differences were found in anthropometric variables, except the increase in the mid-thigh perimeter from before to after training. This finding may be related to increasing isometric knee extension strength $(+4.59$ daN, $\mathrm{p}=0.013$, see Table 3 ) and no differences in weight (Table 2). However, the present study did not control either fat or muscle mass changes.

Previous interventions based on PM exercises were lacking in information about the intervention protocol [11]. However, those with similar interventions to the 

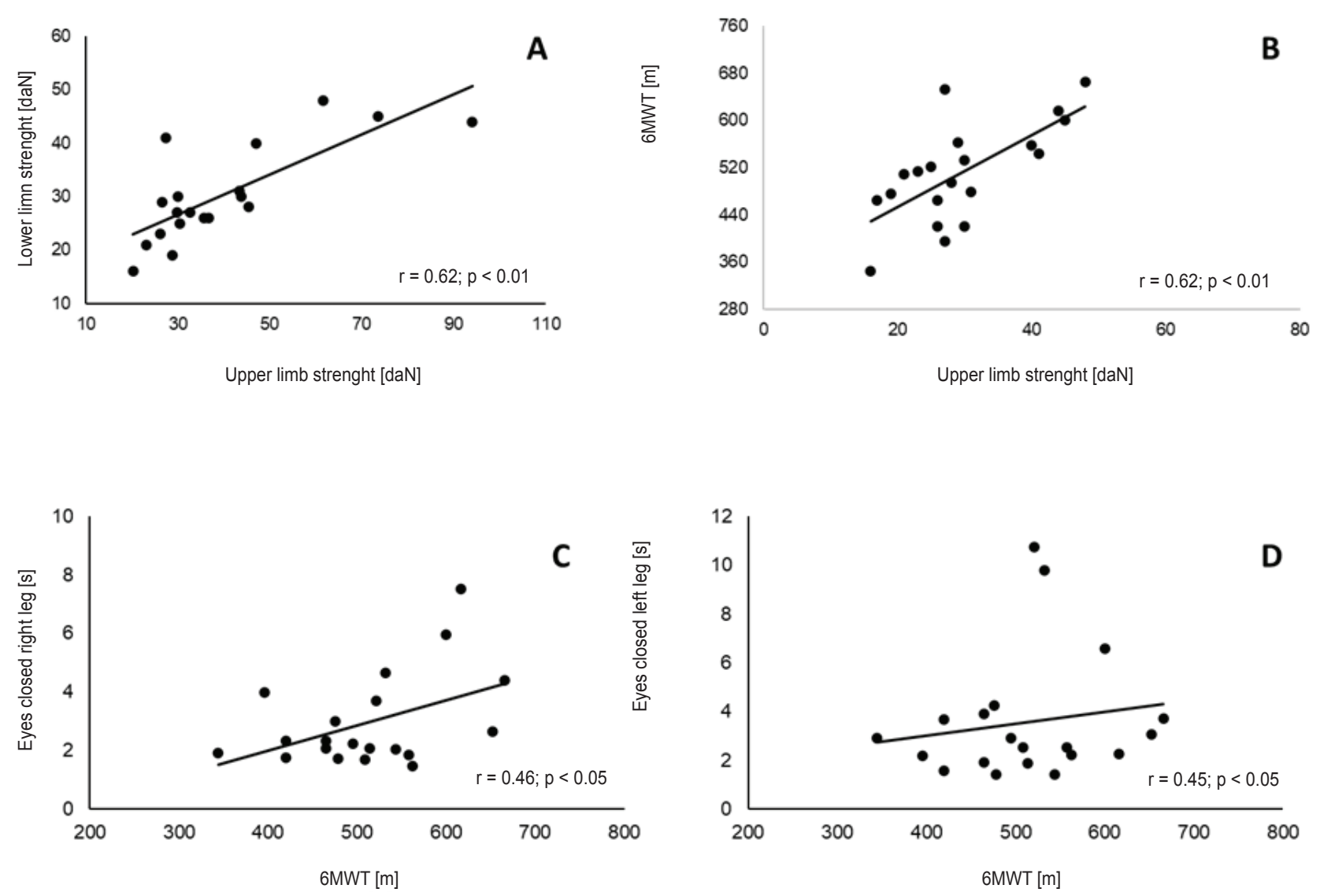

Figure 1. Correlation between muscle strength, cardiorespiratory fitness and balance-related parameters

(A) correlations between lower limb strength and upper limb strength; (B) correlations between cardiorespiratory fitness and upper limb strength; (C) correlations between single leg stance with eyes closed right leg and cardiorespiratory fitness; (D) correlations between single leg stance with eyes closed left leg and cardiorespiratory fitness; 6MWT - six-minute walk test.

present study $[18,48]$ reported important improvements in strength of the lower limbs. Irez et al. (2011) [26] examined the effects of 12-week Pilates exercise intervention on dynamic balance, flexibility, reaction time and muscle strength in order to reduce the number of falls among older women. The study reported a significant improvement in hip flexion, hip adduction and hip abduction strength. Some systematic reviews [9, 14, 32], recent meta-analyses [8] and other research [2] reported strong evidence of increase in lower limb strength after PM mat exercise training. In the present study, besides the increase of dynamic and isometric leg strength, the inclusion of exercises such as squat and lunge exercises, from more conservative to more challenging ranges, might have mediated the positive changes in the lower limb strength in the PT group.

With aging, cardiovascular function seems to be the main determinant in reducing capacity to perform exercise [13]. Most of the PM intervention does not directly include cardiorespiratory fitness parameters. In the review of Cancela et al. (2014) [11], only 4 of 17 studies assessed this parameter while Bullo et al. (2015) [9] reported a small effect on cardiometabolic outcomes. Bueno de Souza et al.
(2018) [8] reported, in a review with meta-analysis, moderate evidence for improvement in cardiovascular fitness after a randomized control trial on Pilates training intervention. Vieira et al. (2017) [49] found, after 12-week Pilates exercises ( 2 times/week, $60 \mathrm{~min} / \mathrm{session}$ ), an increase of $\sim 30 \mathrm{~m}(\mathrm{p}<0.01)$ in the $6 \mathrm{MW}$ test. The present results are in line with this study as a significant increase of $\sim 33.55 \mathrm{~m}(\mathrm{p}=0.047)$ was found in the PT group, in the $6 \mathrm{MW}$. Advancing age results in a reduction in the number of meters walked in the $6 \mathrm{MW}$ test $[37,40]$. Given that, the Pilates method seems to be an important strategy in maintaining or improving the cardiorespiratory fitness and mobility in septuagenarians' daily life activities.

The results of this study also showed that static balance improved significantly either in open eyes or closed eyes condition, in the PT group. In contrast to our findings, Vieira et al. (2017) [49] reported that the one leg stance test remained unaltered after Pilates intervention. Furthermore, the present study found significantly improved lower limb muscle strength assessed as isometric knee extension after an 8-week exercise program, whilst Vieira et al. (2017) [49] reported similar findings, after 
a 12-week exercise program assessed by the five-timessit-to-stand test. In the Vieira et al. (2017) [49] study, the Pilates exercises were conducted using accessory equipment such as exercise rubber bands, Swiss and exercise balls and the participants' mean age was 66 years old. In the present study, the exercises were conducted without accessories and the participants' mean age was 76.5 years. These differences may explain the different results.

Studies using the PM in the elderly have shown a positive effect on the dynamic balance $[3,9,22,26,31,39,48]$. In fact, the present study showed that TUG improved significantly in the PT group, by reducing the time required to perform this test. Increased balance and lower limb muscle strength have been suggested in intervention programs for effectiveness in preventing falls in the elderly [3]. In particular, the strength of the knee extensors has been associated with the performance of activities such as walking and getting up from a chair, as they are decisive to perform functional tests as support unipedal or up and go timed [21]. Our results corroborate these findings since we found significant improvements in the muscle strength of the knee extensors and TUG test in the PT group, the results being better than the 10.2 seconds reference value reported by Bohannon (2006) [5], for people aged 70-79 years.

This study has some limitations. The sample size was limited and was not possible to analyze separated by sex. Additionally, participants' daily life activities such as physical activity, medication and nutrition were not supervised on a daily basis. However, considering the age group and the sample distribution (proportion of men and women in PT and C groups), the effects of the PM on the physical function of elderly people were clear.

The Pilates method based program centered on motor re-education plays a major rule to improve physical fitness for health, especially in cardiorespiratory fitness, lower limb muscle strength and dynamic/static balance in the elderly, over 70 years old.

Thus, this type of exercise training may provide a great help in the maintenance or improvement of functional capacity in the elderly, helping them to perform easily their daily activities and consequently contributing to the social partnership, building a healthier society.

Conflict of interest: Authors state no conflict of interest.

\section{References}

1. Barbat-Artigas S., Filion M.-E., Dupontgand S., Karelis A.D., Aubertin-Leheudre M. (2011) Effects of tai chi training in dynapenic and nondynapenic postmenopausal women. Menopause, 18: 974-979. DOI: 10.1097/ gme.0b013e3182127c89
2. Bertoli J., Dal Pupo J., Vaz M.A., Detanico D., Biduski G.M., de la Rocha Freitas C. (2018) Effects of Mat Pilates on hip and knee isokinetic torque parameters in elderly women. J. Bodyw. Mov. Ther., 22: 798-804. DOI: 10.1016/j.jbmt.2017.08.006.

3. Bird M.L., Hill K.D., Fell J.W. (2012) A Randomized Controlled Study Investigating Static and Dynamic Balance in Older Adults After Training With Pilates. Arch. Phys. Med. Rehabil., 93: 43-49. DOI: 10.1016/j. apmr.2011.08.005.

4. Blain H., Jaussent A., Thomas E., Micallef J.P., Dupuy A.M., Bernard P.L., Mariano-Goulart D., Cristol J.P., Sultan C., Rossi M., Picot M.C. (2010) Appendicular skeletal muscle mass is the strongest independent factor associated with femoral neck bone mineral density in adult and older men. Exp. Gerontol., 45: 679-684. DOI: 10.1016/j.exger.2010.04.006.

5. Bohannon R.W. (2006) Reference values for the timed up and go test: a descriptive meta-analysis. J. Geriatr. Phys. Ther., 29: 64-68. DOI: 10.1519/00139143-20060800000004.

6. Bohannon R.W., Bubela D.J,, Wang Y.C., Magasi S.S., Gershon R.C. (2013) Six-minute Walk Test versus Threeminute Step Test for Measuring Functional Endurance. J. Strength Cond. Res., 29: 3240-3244. DOI: 10.1519/ jsc.0000000000000253.

7. Brady A.O., Straight C.R. (2014) Muscle capacity and physical function in older women: What are the impacts of resistance training? J. Sport Health Sci., 3: 179-188. DOI: 10.1016/j.jshs.2014.04.002.

8. Bueno de Souza R.O., Marcon L. de F., Arruda A.S.F. de, Pontes Junior F.L., Melo R.C. de (2018) Effects of Mat Pilates on Physical Functional Performance of Older Adults: A Meta-analysis of Randomized Controlled Trials. Am. J. Phys. Med. Rehabil., 97: 414-425. DOI: 10.1097/PHM.0000000000000883.

9. Bullo V., Bergamin M., Gobbo S., Sieverdes J.C., Zaccaria M., Neunhaeuserer D., Ermolao A. (2015) The effects of Pilates exercise training on physical fitness and wellbeing in the elderly: A systematic review for future exercise prescription. Prev. Med., (Baltim) 75: 1-11. DOI: 10.1016/j.ypmed.2015.03.002.

10. Cadore E.L., Rodriguez-Manas L., Sinclair A., Izquierdo M. (2013) Effects of Different Exercise Interventions on Risk of Falls, Gait Ability, and Balance in Physically Frail Older Adults: A Systematic Review. Rejuvenation Res., 16: 105-114. DOI: 10.1089/rej.2012.1397.

11. Cancela J.M., de Oliveira I.M., Rodríguez-Fuentes G. (2014) Effects of Pilates method in physical fitness on older adults. A systematic review. Eur. Rev. Aging Phys. Act., 11: 81-94. DOI: 10.1007/s11556-014-0143-2

12. Carvalho M.J., Marques E., Mota J. (2009) Training and Detraining Effects on Functional Fitness after a Multi- 
component Training in Older Women. Gerontology, 55: 41-48. DOI: 10.1159/000140681.

13. Chodzko-Zajko W.J., Proctor D.N., Fiatarone Singh M.A., Minson C.T., Nigg C.R., Salem G.J., Skinner J.S. (2009) Exercise and Physical Activity for Older Adults. Med. Sci. Sport Exerc., 41: 1510-1530. DOI: 10.1249/ MSS.0b013e3181a0c95c.

14. Costa L.M.R. da, Schulz A., Haas A.N., Loss J. (2016) The Effects of Pilates on the Elderly: An Integrative Review. Rev. Bras. Geriatr. Gerontol., 19: 695-702. DOI: 10.1590/1809-98232016019.150142.

15. Engers P.B., Rombaldi A.J., Portella E.G., da Silva M.C. (2016) The effects of the Pilates method in the elderly: a systematic review. Rev. Bras. Reumatol., 56: 352-365. DOI: $10.1016 /$ j.rbre.2016.05.005.

16. Fernández Roldán K., Benítez Jiménez A. (2013) Influencia de la práctica del método pilates sobre la sarcopenia. Kronos XII, 12: 51-55.

17. Fess E., Moran C. (1981) American Society of Hand Therapists Clinical Assessment Recommendations, $1^{\circ}$. American Society of Hand Therapists.

18. Fourie M., Gildenhuys G.M., Shaw I., Shaw B.S., Toriola A.L., Goon D.T. (2013) Effects of a mat Pilates programme on body composition in elderly women. West Indian Med. J., 62: 524-528. DOI: 10.7727/ wimj.2012.107.

19. Fried L.P., Ferrucci L., Darer J., Williamson J.D., Anderson G. (2004) Untangling the Concepts of Disability, Frailty, and Comorbidity: Implications for Improved Targeting and Care. J. Gerontol. Ser. A, 59: M255-M263. DOI: 10.1093/gerona/59.3.M255.

20. Geirsdottir O.G., Arnarson A., Briem K., Ramel A., Tomasson K., Jonsson P.V., Thorsdottir I. (2012) Physical function predicts improvement in quality of life in elderly Icelanders after 12 weeks of resistance exercise. J. Nutr. Health Aging, 16: 62-66. DOI: 10.1007/s12603-0110076-7.

21. Hernandez M.E., Goldberg A., Alexander N.B. (2010) Decreased Muscle Strength Relates to Self-Reported Stooping, Crouching, or Kneeling Difficulty in Older Adults. Phys. Ther., 90: 67-74. DOI: 10.2522/ptj.20090035.

22. Herting M.M., Nagel B.J. (2013) Differences in Brain Activity during a Verbal Associative Memory Encoding Task in High- and Low-fit Adolescents. J. Cogn. Neurosci., 25: 595-612. DOI: 10.1162/jocn_a_00344.

23. Hopkins K.D., Hopkins B.R., Glass G.V. (1996) Basic statistics for the behavioral sciences. Allyn and Bacon, Boston.

24. Hrysomallis C. (2011) Balance ability and athletic performance. Sports Med., 41: 221-232. DOI: 10.2165/11538560-000000000-00000.

25. Innes E. (1999) Handgrip strength testing: A review of the literature. Aust. Occup. Ther. J., 46: 120-140. DOI: 10.1046/j.1440-1630.1999.00182.x.
26. Irez G.B., Ozdemir R.A., Evin R., Irez S.G., Korkusuz F. (2011) Integrating Pilates exercise into an exercise program for $65+$ year-old women to reduce falls. J. Sports Sci. Med., 10: 105-111.

27. Kaesler D., Mellifont R., Swete Kelly P., Taaffe D. (2007) A novel balance exercise program for postural stability in older adults: A pilot study. J. Bodyw. Mov. Ther., 11: 37-43. DOI: 10.1016/j.jbmt.2006.05.003.

28. Lavin K.M., Perkins R.K., Jemiolo B., Raue U., Trappe S.W., Trappe T.A. (2020) Effects of aging and lifelong aerobic exercise on basal and exercise-induced inflammation. J. Appl. Physiol., 128: 87-99. DOI: 10.1152/japplphysiol.00495.2019.

29. Marques E.A., Baptista F., Santos R., Vale S., Santos D.A., Silva A.M., Mota J., Sardinha L.B. (2014) Normative Functional Fitness Standards and Trends of Portuguese Older Adults: Cross-Cultural Comparisons. $J$. Aging Phys. Act., 22: 126-137. DOI: 10.1123/japa.20120203.

30. Mezzaroba P.V., Prati A.R.C. (2012) Influence of strength training on variables related to elderly autonomy. Acta Sci. Health Sci., 34: 157-162. DOI: 10.4025/actascihealthsci.v34i2.8927.

31. Mokhtari M., Nezakatalhossainib M., Esfarjanic F. (2013) The effect of 12-week pilates exercises on depression and balance associated with falling in the elderly. Procedia-Soc. Behav. Sci., 70: 1714-1723. DOI: 10.1016/j. sbspro.2013.01.246.

32. Moreno-Segura N., Igual-Camacho C., Ballester-Gil Y., Blasco-Igual M., Blasco J. (2017) The Effects of the Pilates Training Method on Balance and Falls of Older Adults: A Systematic Review and Meta-Analysis of Randomized Controlled Trials. J. Aging Phys. Act., 26: 327-344. DOI: 10.1123/japa.2017-0078.

33. National Institutes of Health (1998) Clinical Guidelines on the Identification, Evaluation, and Treatment of Overweight and Obesity in Adults - The Evidence Report. National Institutes of Health. Obes. Res. 6 Suppl 2: 51s-209s

34. Pallant J. (2011) SPSS Survival Manual: A Step by Step Guide to Data Analysis Using the SPSS Program. Allen \& Unwin, Australia.

35. Paterson D.H., Warburton D.E.R. (2010) Physical activity and functional limitations in older adults: a systematic review related to Canada's Physical Activity Guidelines. Int. J. Behav. Nutr. Phys. Act., 7. DOI: 10.1186/14795868-7-38.

36. Podsiadlo D., Richardson S. (1991) The Timed Up and Go - A test of Basic Functional Mobility for frail Elderly Persons. J. Am. Geriatr. Soc., 39: 142-148. DOI: 10.1111/j.1532-5415.1991.tb01616.x.

37. Rikli R.E., Jones C.J. (2013) Development and Validation of Criterion-Referenced Clinically Relevant Fitness Standards for Maintaining Physical Independence in 
Later Years. Gerontologist, 53: 255-267. DOI: 10.1093/ geront/gns071.

38. Rocha-Rodrigues S., Silva B., Camões M. Rodrigues L.P., Bezerra P. (2019) Bone mineral density and muscle strength in elderly: a cross-sectional study. In: International Seminar of Physical Education, Leisure and Health. Journal of Human Sport and Exercise, Castelo Branco, pp. S1169-S1823.

39. Rodrigues B., Cader S., Torres N., Oliveira E.M. de, Dantas E., Siqueira Rodrigues B.G. de, Ali Cader S., Bento Torres N.V.O., Oliveira E.M. de, Martin Dantas E.H. (2010) Pilates method in personal autonomy, static balance and quality of life of elderly females. J. Bodyw. Mov. Ther., 14: 195-202. DOI: 10.1016/j.jbmt.2009.12.005.

40. Sardinha L.B., Santos D.A., Marques E.A., Mota J. (2015) Criterion-referenced fitness standards for predicting physical independence into later life. Exp. Gerontol., 61: 142-146. DOI: 10.1016/j.exger.2014.12.012.

41. Silva Y.O., Melo M.O., Gomes L.E., Bonezi A., Loss J.F. (2009) Analysis of the external resistance and electromyographic activity of hip extension performed according to the Pilates method. Rev. Bras. Fisioter., 13: 82-88. DOI: 10.1590/S1413-35552009005000010.

42. Society A.T., Crapo R., Casaburi R., Coates A., Enright P., MacIntyre N., McKay R., Johnson D., Wanger J., Zwbalos R., Bittner V., Mottram C. (2002) ATS Statement: guidelines for the Six-Minute Walk Test. Am. J. Respir. Crit. Care Med., 166: 111-117. DOI: 10.1164/ ajrccm.166.1.at1102.

43. Springer B.A., Marin R., Cyhan T., Roberts H., Gill N.W. (2007) Normative Values for the Unipedal Stance Test with Eyes Open and Closed. J. Geriatr. Phys. Ther., 30: 8-15. DOI: 10.1519/00139143-200704000-00003.

44. Stewart A., Marfell-Jones M., Olds T., De Ridder J. (2011) International Standards for Anthropometric Assessment. International Society for the Advancement of Kinanthropometry.
45. Sturnieks D.L., George R.St., Lord S.R. (2008) Balance disorders in the elderly. Neurophysiol. Clin., 38: 467-478. DOI: 10.1016/j.neucli.2008.09.001.

46. United Nations (2015) World Population Ageing 2015. Population Division.

47. Valenzuela P.L., Castillo-García A., Morales J.S., Izquierdo M., Serra-Rexach J.A., Santos-Lozano A., Lucia A. (2019) Physical Exercise in the Oldest Old. Compr. Physiol., 9: 1281-1304. DOI: 10.1002/cphy.c190002.

48. Vécseyné Kovách M., Kopkáné Plachy J., Bognár J., Olvasztóné Balogh Z., Barthalos I. (2013) Effects of Pilates and aqua fitness training on older adults' physical functioning and quality of life. Biomed. Hum. Kinet., 5: 22-27. DOI: 10.2478/bhk-2013-0005.

49. Vieira N.D., Testa D., Ruas P.C., Salvini T. de F., Catai A.M., Melo R.C. (2017) The effects of 12 weeks Pilatesinspired exercise training on functional performance in older women: A randomized clinical trial. J. Bodyw. Mov. Ther., 21: 251-258. DOI: 10.1016/j.jbmt.2016.06.010.

50. Wang Y.C., Bohannon R.W., Magasi S.R., Hrynkiewicz B., Morales A., Gershon R.C., Rymer Z. (2011) Testing of knee extension muscle strength: A comparison of two portable alternatives for the NIH toolbox study. Isokinet. Exerc. Sci., 19: 163-168. DOI: 10.3233/IES-2011-0410

51. Yu D.-H., Yang H.-X. (2012) The effect of Tai Chi intervention on balance in older males. J. Sport Health Sci., 1: 57-60. DOI: 10.1016/j.jshs.2012.03.001.

\section{Received 02.09.2020 \\ Accepted 01.10.2020}

(C) University of Physical Education, Warsaw, Poland

Acknowledgments

The authors would like to thank all participants for their availability in collecting the data. 